In Memoriam

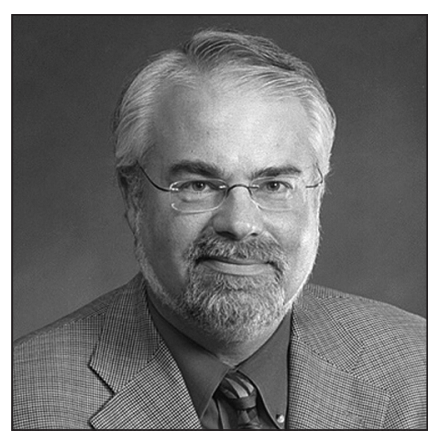

Christopher E. Desch, MD
Journal of the National Comprehensive Cancer Network

\section{In Memoriam: Christopher E. Desch, MD}

\author{
Nothing endures but personal qualities. \\ Walt Whitman
}

By Rodger J. Winn, MD

It is easy to measure the loss of Dr. Christopher Desch by recounting his considerable accomplishments: the seminal studies in cancer-related health services research during his early years at the Medical College of Virginia, the clinical research programs he began in the Community Clinical Oncology Program (CCOP) and private practice venues, the leadership position he held in an exemplary oncology practice, the pre-eminent positions he held in ASCO. If I had to point to one achievement that epitomized his career, it would be the rural oncology program he initiated and still staffed, bringing expert oncologic care to all reaches of country-side Virginia. We at NCCN can especially single out the benefits we accrued from Chris's all-too-short tenure as medical director: launching a quality measure program, strengthening the guidelines process, and helping refine JNCCN itself.

But, professional accomplishments aside, it is the man we miss and mourn. Chris, the man, brought to each of his endeavors a quality we see too infrequently in today's hard-edged, increasingly corporate world of oncology practice-zeal. And it was zeal committed to one principle, one goal: getting better care for cancer patients. Although his manner was soft-spoken and self-effacing, Chris' passion shone forth. He had an underlying steely determination to raise standards at all levels of care. His probing questions, often astonishing insights, and outside-the-box thinking forced discussions to higher levels. His remarkable people skills allowed him to simultaneously ruffle and smooth feathers, ultimately driving his colleagues to accept his principles and become co-aspirers. Quality of care was not a niche, it was a raison d'etre.

Chris, the man, was a good man, and a good friend.

But even without the man among us, the zeal endures. Those of us who knew Chris and were touched by this remarkable man, now carry his legacy. We will endeavor to be worthy. 